\title{
Effective removal of air pollutions by the electrical discharge
}

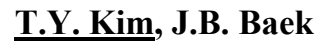

Korea National University of Transportation

Email:sobm00@gmail.com

\begin{abstract}
Environmental pollution is one of the greatest man-made problems of our time and happens when the air includes harmful gases, dust or fumes in harmful amounts. It can be serious to human and animals' health or can generate damage to plants and materials.
\end{abstract}

Air pollutants are strongly associated with diseases, such as, respiratory infections, adverse effect on nervous system and so on. Some forms of air pollution create photochemical smog, greenhouse effect, climate change, ozone layer depletion and acid rain.

Non-thermal plasma is an attractive option for the pollution control due to their high efficiency for producing radicals and oxidizing agents for strong energetic chemical reactions without heating the bulk of the gas. Even if electrons are short lived at atmospheric pressure and collide infrequently with the pollutant molecules, they make many collisions with the dominant background gas molecules and produce radicals through electron-impact dissociation and ionization.

Removal of NOx with a dielectric barrier discharge reactor is conducted in this study. The surface discharges are applied to the reactors and the removal efficiency is compared with different electrode shapes and frequencies. The applied voltage, current, frequency and the electrode shape are applied as main variables.

In general, it has been known that the removal efficiency is decided by the applied power, which is calculated by multiplication of the applied voltage and current. However, it is known in this study that the removal efficiency significantly depends on the composition ratio of the applied voltage and current even though the experimental conditions are not changed even with the same applied power. It means that the removal effectiveness should be considered by the applied voltage and current separately.

The objectives of this study are

- To understand the effects of different electrical and reactor structure parameters on the pollutant removal efficiency

- To optimize reactor parameters to achieve the highest removal efficiency

- To present the technologically feasible and economically attractive discharge system to improve the efficiency

From the experimental and statistical analysis, we found the following results.

- The applied power should be divided into the voltage and current to investigate their individual effects on NOx removal even though the discharge power can be to express the energy efficiency.

- Right decision of the value of the applied voltage, current and frequency is important to maximize the removal efficiency.

- The discharge current is the most important factor to control the removal rate regardless of different types of the reactor.

- The frequency is not the direct function to control the removal rate but is the indirect function to control the removal rate through the effect on the applied voltage and current.

Keywords: Non-thermal plasma, electrical discharge, air pollution 


\section{INTRODUCTION}

Air pollutants are strongly associated with diseases, such as, intrauterine mortality, different pregnancy outcome, low birth weight, respiratory infections and adverse effect on nervous system and so on. Fine PM and ozone are associated with increasing risk of mortality and respiratory morbidity, while exposure to nitrogen oxides, ozone and PM is linked with allergic responses.

Especially, GHG and fine PM are serious problem in Korea and GHG are still increasing significantly compared with OECD average because higher economic growth than other OECD countries in Figure 1 Figure 2 .

In early 2000, plasma technology was recognized as new attractive method to control air pollutions and it was expected to change chemical method into ecofriendly method. However, without the chemical method, such as bag filters, it was hard to control byproducts and to improve the energy efficiency.

In spite of some disadvantages of the plasma technology, the electrical discharges as one of the plasma technology has been applied to purify waste water and to prevent malodor from manufacturing processes widely in Korea due to excellent ability of $\mathrm{O}_{3}$ generation.

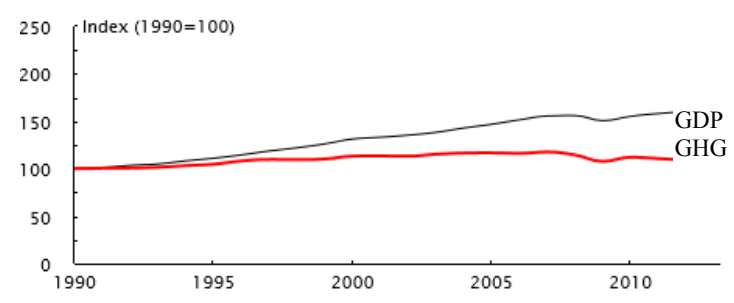

Figure 1. GHG emission of OECD

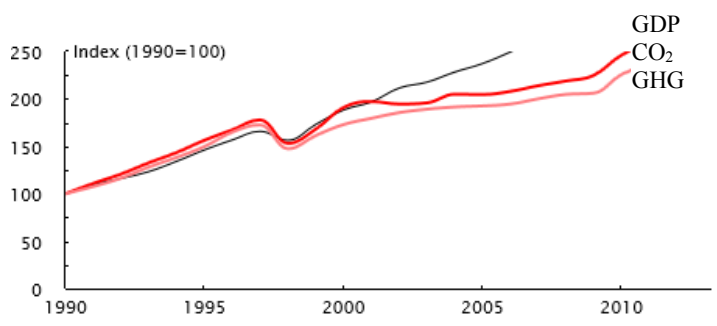

Figure 2. GHG emission of Korea

Previous studies that removal efficiency for the removal of air pollutions or the generation of ozone should be been decided by the applied discharge power or discharge voltage because that the generation of the discharge mainly depends on the applied voltage and the energy consumption depends on the applied power calculated by multiplication of the applied voltage and current.

In this study, it is shown that NOx reduction and reactant generation are decided not by the discharge power but by multiple combinations of different experimental variables and the individual or mutual effects of the variables has been investigated.

\section{EXPERIMENTAL SET UP}

The chemical reactions are carried out in tubular dielectric barrier discharge reactors with different arrangements of electrodes.

For the surface discharge, the tungsten wire is attached on the outside surface of the inside tube, which is activated as a dielectric barrier and filled with metal balls. The use of a Pyrex tube allows inspection of the inside of a discharge reactor. The effective discharge length is $115 \mathrm{~mm}$.

Number of turn of the tungsten wire is decided by the

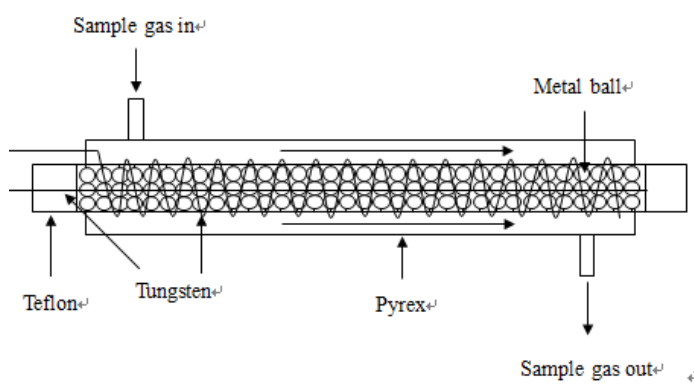

Figure 3. Surface discharge reactor distance between wires and varies from 4, 9 and 20 turns. The applied frequency is raised from $1 \mathrm{kHz}$ up to $9 \mathrm{kHz}$ and the voltage is applied from several hundred voltage up to $5 \mathrm{kV}$. A gas flow rate is set at $1 \mathrm{~L} / \mathrm{min}$ creating a residence time of $0.83 \mathrm{~s}$. NOx $1,000 \mathrm{ppm}$ balanced by $\mathrm{N}_{2}$ is employed.

\section{EXPERIMENTAL RESULTS}

\subsection{NOx removal rate}

Different frequencies $(1 \sim 9 \mathrm{kHz})$ are applied to three different reactors, which are classified by the number of electrode turns, to investigate their effects on NOx removal. Experimental results are compared in Figure 4 Figure 6. 


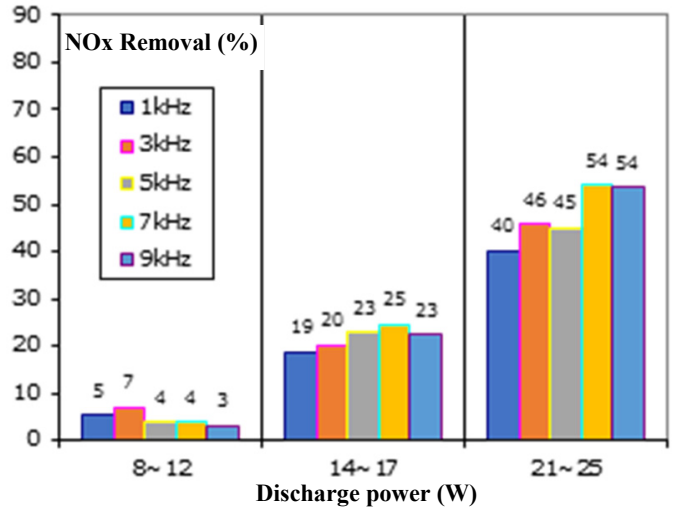

Figure 4. NOx removal rate of 4 turn reactor

It is shown that the increase of the applied frequency improves the removal rate at the similar applied power even though their effects seem to level off after $7 \mathrm{kHz}$.

At the start of the discharge, it seems that higher removal is expected with low frequencies. However, the highest removal rate is obtained with the application of $7 \mathrm{kHz}$ regardless of different electrode configuration.

The change of the applied frequency affects the impedance of the dielectric barrier reactor and the ratio of the applied voltage and current.

It is known from the experimental result that the removal rate is significantly affected by the combination of the applied voltage and current because the removal is controlled not by the frequency but by the applied power by multiplication of the applied voltage and current.

\subsection{Effect of frequency and design of the reactor on NOx removal}

All discharge V-I proportion obtained by experimental results are compared and three groups, which shows the same applied power, voltage and current, are found in Figure 7. $T$ and $k$ means the number of the electrode turn and applied frequency respectively.

This comparison removes the effect of different combination of the voltage and current and makes to focus the effect of the frequency and electrode configuration on NOx removal.

It is shown in Figure 8 that the removal rate is significantly different depending on the applied frequency and electrode configuration even though the applied power, voltage and current are not different.

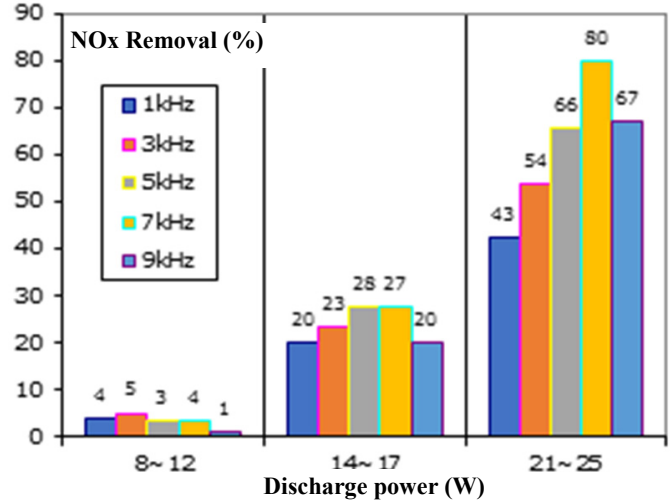

Figure 5. NOx removal rate of 9 turn reactor

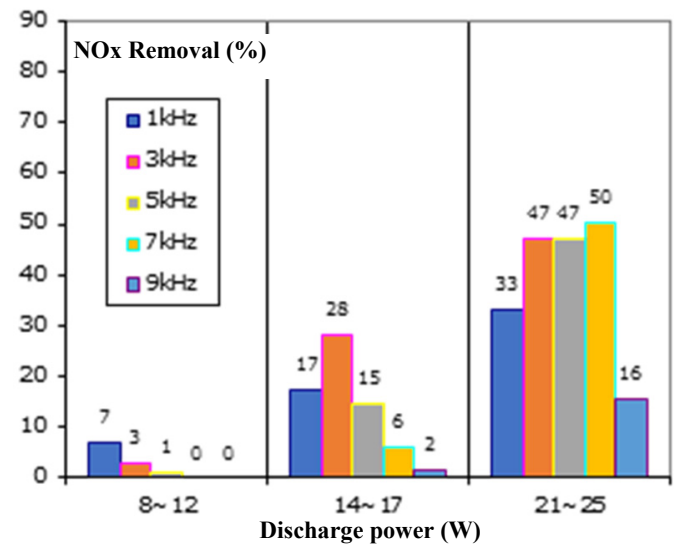

Figure 6. NOx removal rate of 20 turn reactor

Therefore, the combination of the applied voltage and current should be investigated to reach the top of the removal efficiency whenever the configuration of the electrode the reactor is modified. Based on the investigation, the right decision of the design of the electrode and reactor is important to improve NOx removal and it is confirmed again that the frequency is not related to NOx removal directly but is connected to other experimental functions closely. 

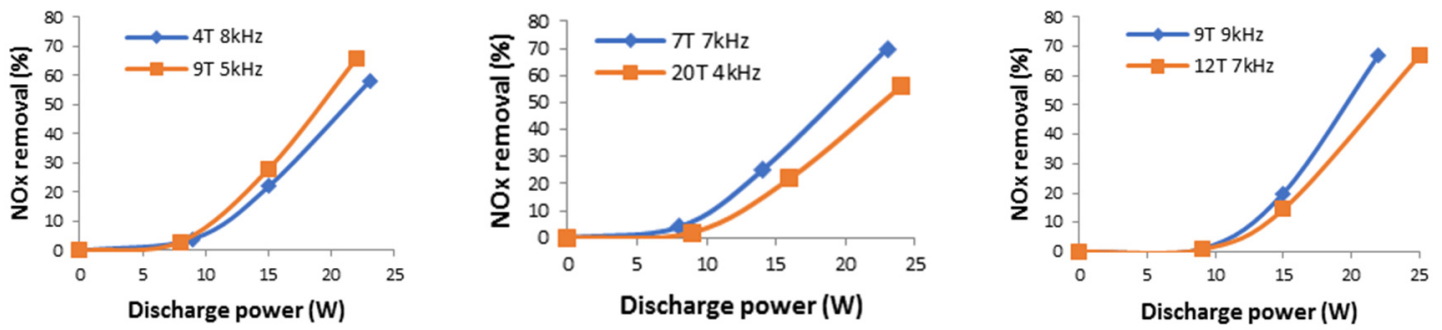

Figure 8. NOx removal focused on the effect of the frequency and electrode

From the experimental results,

- The applied power should be divided into the voltage and current to investigate their individual effects on NOx removal because different removal rates are observed even though the same power is applied to the same reactor.

- The increase of the applied frequency increases the removal efficiency with the same reactor even though the positive effect of the frequency is limited.

- $\quad$ Right decision of the applied voltage, current and frequency should be done carefully to improve the removal efficiency because they are closely connected each other.

\section{STATISTICAL ANALYSIS}

\subsection{Voltage, current, frequency and electrode configuration}

Based on the experimental results, main functions are decided as the applied voltage(V), current(I), frequency $(\mathrm{F})$ and electrode configuration(T). 348 experimental samples are statistically analyzed to investigate individual effects of the functions on the removal to understand the most important factor for the removal efficiency.

It is shown in Table $\mathbf{1}$ that the discharge voltage and current have positive correlation to NO decomposition but the negative correlation of DeNO is indicated by the increase of the electrode turn.

It is statistically confirmed that the frequency has no correlation to DeNO directly but has strong relation to the voltage and current as expected.

From this analysis, it is expected that the most important factor to control NO removal is the discharge current.

Table 1. Correlation analysis of variances

\begin{tabular}{|c|c|c|c|c|c|c|}
\hline & & Voltage & Current & Freq & Turns & DeNO \\
\hline \multirow{3}{*}{$\begin{array}{l}\text { Voltage } \\
\text { (V) }\end{array}$} & Pearson Correlation & 1 & $-.234^{* *}$ & $-.757^{* *}$ & $-.183^{* *}$ & $.320^{* *}$ \\
\hline & Sig. (2-tailed) & & .000 & .000 & .001 & .000 \\
\hline & $\mathrm{N}$ & 348 & 348 & 348 & 348 & 348 \\
\hline \multirow{3}{*}{$\begin{array}{l}\text { Current } \\
\text { (I) }\end{array}$} & Pearson Correlation & $-.234^{* *}$ & 1 & $.503^{* *}$ & $.205^{* *}$ & $.738^{* *}$ \\
\hline & Sig. (2-tailed) & .000 & & .000 & .000 & .000 \\
\hline & $\mathrm{N}$ & 348 & 348 & 348 & 348 & 348 \\
\hline \multirow{3}{*}{$\begin{array}{l}\text { Freq } \\
(\mathrm{F})\end{array}$} & Pearson Correlation & $-.757^{* *}$ & $.503^{* *}$ & 1 & $-.129^{*}$ & .002 \\
\hline & Sig. (2-tailed) & .000 & .000 & & .016 & .963 \\
\hline & $\mathrm{N}$ & 348 & 348 & 348 & 348 & 348 \\
\hline \multirow{3}{*}{$\begin{array}{l}\text { Turn } \\
\text { (T) }\end{array}$} & Pearson Correlation & $-.183^{* *}$ & $.205^{* *}$ & $-.129^{*}$ & 1 & $-.116^{*}$ \\
\hline & Sig. (2-tailed) & .001 & .000 & .016 & & .031 \\
\hline & $\mathrm{N}$ & 348 & 348 & 348 & 348 & 348 \\
\hline \multirow{3}{*}{ DeNO } & Pearson Correlation & $.320^{* *}$ & $.738^{* *}$ & .002 & $-.116^{*}$ & 1 \\
\hline & Sig. (2-tailed) & .000 & .000 & .963 & .031 & \\
\hline & $\mathrm{N}$ & 348 & 348 & 348 & 348 & 348 \\
\hline
\end{tabular}

** Correlation is significant at the 0.01 level (2-tailed)

* Correlation is significant at the 0.05 level (2-tailed)

Model summary by MLR(Multiple Linear Regression) with VIFT is shown in Table 2. A stepwise multiple regression analysis, which applies significant variables in order and then rejects non-significant variables, is applied.

Four models are proposed by the stepwise method and the fourth model, which has four predictors, explains the relation between the dependent and independent variables better than others.

Table 2. Model summary ${ }^{\mathrm{e}}$

\begin{tabular}{l}
\begin{tabular}{|c|r|r|r|r|}
\hline Model & \multicolumn{1}{c|}{$\mathrm{R}$} & \multicolumn{1}{c|}{ R Square } & Adjusted R Square & Std. Error of the Estimate \\
\hline 1 & $.738^{\mathrm{a}}$ & .545 & .544 & 146.738 \\
\hline 2 & $.896^{\mathrm{b}}$ & .803 & .801 & 96.797 \\
\hline 3 & $.919^{\mathrm{c}}$ & .844 & .843 & 86.166 \\
\hline 4 & $.947^{\mathrm{d}}$ & .896 & .895 & 70.462 \\
\hline
\end{tabular} \\
\hline a. Predictors : (Constant), Current \\
b. Predictors : (Constant), Current, Voltage \\
c. Predictors : (Constant), Current, Voltage, Turn \\
d. Predictors : (Constant), Current, Voltage, Turn, Frequency \\
e. dependent: DeNOx
\end{tabular}


R-square for this model is .896 which means that the $\mathrm{X}$ variables can explain about $89.6 \%$ of the change in $\mathrm{Y}$.

It is indicated in 4 th model of Table 3 that the increase of $1 \mathrm{~mA}$ or $1 \mathrm{kV}$ removes NO $151 \mathrm{ppm}$ or $27 \mathrm{ppm}$ respectively but that of the increase of the frequency or electrode turn deteriorates NO removal. It is known that positive effect of the increase of the frequency is limited as expect.

It is observed that the effect of the voltage is significantly reduced at the 4th model compared with the 3rd model and only difference between two models is the existence of the frequency.

This happens because of the negative correlation between the frequency and the voltage. The regression equation is shown in the below.

$$
\mathrm{Y}=-94.4+(153.2 \times \text { Current })+(27.0 \times \text { Voltage })-(16.5 \times \text { Turn })-(42.2 \times \text { Frequency })
$$

\subsection{Comparison of VIFT and PFT}

Statistical analysis is conducted in Table 4 with the discharge power instead of the voltage and current.

It is shown that the most important factor is the discharge power for the improvement of the removal. It is also shown that the increase of the applied frequency and electrode turn increase the removal efficiency.

From the experimental results, it is known that there is the limitation to increase the removal efficiency with increasing the frequency and electrode turn and the removal is seriously deteriorated after the limitation. The effect of the frequency can be overestimated or distorted.

From the statistical results,

- The discharge current is the most important factor to control the removal rate regardless of different types of the reactor.

- The frequency is not the direct function to control the removal rate but is the indirect function to control the applied voltage and current.

- The discharge power is applied to express the energy efficiency. However, to maximize the removal and energy efficiency and to set the ideal design for the reactor or electrode, it is necessary that the applied voltage and current should be investigated respectively instead of the applied power.

\section{DISCUSSION AND CONCLUSIONS}

Experiments and statistical analysis are conducted to find out the ideal conditions for the effective removal of air pollutions. In most of previous studies, the discharge power has been widely applied to compare the removal efficiency, to prove the removal abilities and to design the effective reactor.

However, it is confirmed that the discharge power should be divided into the discharge voltage and current to investigate to improve the removal efficiency and another important reason of the application of the voltage and current is for the design of the reactor. Without the investigation of the voltage and current respectively, it is impossible to make the reactor work well. 
T. Y. Kim et al., Effective removal of air pollutions by the electrical discharge

Conclusions are the below

- The applied power should be divided into the voltage and current to investigate their individual effects on NOx removal even though the discharge power can be to express the energy efficiency.

- $\quad$ Right decision of the value of the applied voltage, current and frequency is important to maximize the removal efficiency.

- The discharge current is the most important factor to control the removal rate regardless of different types of the reactor.

- The frequency is not the direct function to control the removal rate but is the indirect function to control the removal rate through the effect on the applied voltage and current.

\section{REFERENCES}

OECD Environmental Indicators. http://www.oecd.org/site/envind/korea.htm.

Ji-Young Son, Michelle L. Bell and Jong-Tae Lee (2011). Survival Analysis of Long-Term Exposure to Different Sizes of Airborne Particular Matter and Risk of Infant Mortality Using a Birth Cohort in Seoul, Korea. National Center for Biotechnology Information, 119(5), 725-730.

Toshikazu Nomura, Yoshiyasu Ehara, Tairo Ito, Minoru Matsuyama. (2000). Effect of applied voltage frequency on NOx removal rate for a superimposing discharge reactor. Journal of Electrostatics, 49, 8393.

Laroussi, M., Alexeff, I., Richardson, J.P., Dyer, F.F. (2002). The resistive barrier discharge. IEEE Transactions on Plasma Science. 30. 158-159.

Y. Kawada, T. Kaneko, T. Ito, J.S. Chang (2001). Barrier discharge characteristics of wire-pole electrodes with ferro-electric barriers. Electrical Insulation and Dielectric Phenomena, 2001 Annual Report. Conference on. 388-391 